\title{
Estimated Budget Impact of Adopting the Affordable Care Act's Required Smoking Cessation Coverage on United States Healthcare Payers
}

\author{
Christine L. Baker • Cheryl P. Ferrufino · Marianna Bruno • \\ Stacey Kowal
}

Received: September 28, 2016 / Published online: November 25, 2016

(c) The Author(s) 2016. This article is published with open access at Springerlink.com

\section{ABSTRACT}

Introduction: Despite abundant information on the negative impacts of smoking, more than 40 million adult Americans continue to smoke. The Affordable Care Act (ACA) requires tobacco cessation as a preventive service with no patient cost share for all FDA-approved cessation medications. Health plans have a vital role in supporting smoking cessation by managing medication access, but uncertainty remains on the gaps between smoking cessation requirements and what is actually occurring in practice. This study presents current cessation patterns, real-world drug costs and plan benefit design data, and estimates the 1- to 5-year

Enhanced content To view enhanced content for this article go to www.medengine.com/Redeem/ E127F0604E77033C.

Electronic supplementary material The online version of this article (doi:10.1007/s12325-016-0446-y) contains supplementary material, which is available to authorized users.

C. L. Baker · M. Bruno

Pfizer Inc, New York, NY, USA

C. P. Ferrufino $\cdot$ S. Kowal $(\bowtie)$

Health Economics and Outcomes Research, IMS

Health, Fairfax, VA, USA

e-mail: skowal@us.imshealth.com pharmacy budget impact of providing ACA-required coverage for smoking cessation products to understand the fiscal impact to a US healthcare plan.

Methods: A closed cohort budget impact model was developed in Microsoft Excel ${ }^{\circledR}$ to estimate current and projected costs for US payers (commercial, Medicare, Medicaid) covering smoking cessation medicines, with assumptions for coverage and smoking cessation product utilization based on current, real-world national and state-level trends for hypothetical commercial, Medicare, and Medicaid plans with 1 million covered lives. A Markov methodology with five health states captures quit attempt and relapse patterns. Results include the number of smokers attempting to quit, number of successful quitters, annual costs, and cost per-member per-month (PMPM).

Results: The projected PMPM cost of providing coverage for smoking cessation medications is $\$ 0.10$ for commercial, $\$ 0.06$ for Medicare, and $\$ 0.07$ for Medicaid plans, reflecting a low incremental PMPM impact of covering two attempts ranging from $\$ 0.01$ for Medicaid to $\$ 0.02$ for commercial and Medicare payers. 
Conclusion: The projected PMPM impact of covering two quit attempts with access to all seven cessation medications at no patient cost share remains low. Results of this study reinforce that the impact of adopting the ACA requirements for smoking cessation coverage will have a limited near-term impact on health plan's budgets.

Funding: Pfizer Inc.

Keywords: Affordable Care Act; Budgetary impact; Pharmacotherapy; Smoking cessation; Tobacco control; Varenicline

\section{INTRODUCTION}

Cigarette smoking is a serious public health concern and, despite ongoing educational efforts, it remains the leading preventable cause of death in the USA [1]. Recent data from the Centers for Disease Control and Prevention and national cohort studies indicate that smoking is causally, or suspected causally, related to approximately 500,000 deaths each year [1-3]. Smoking is responsible for approximately $87 \%$ of all lung cancer deaths, $80-90 \%$ of chronic obstructive lung disease, and $32 \%$ of heart disease deaths [1]. In addition to the significant mortality burden, cigarette smoking exacts a striking financial burden, accounting for an estimated $\$ 133$ to $\$ 176$ billion in direct medical care costs, $\$ 151$ billion in lost productivity from premature death, and almost $\$ 6$ billion due to lost productivity from secondhand smoke exposure in the USA alone [1]. Despite this abundance of information on the negative health and economic impacts of smoking, more than 40 million adult Americans (15.1\% of adults) continue to smoke cigarettes [4].
Though the negative effects of smoking are considerable, smoking cessation has immediate and lasting impacts on smoker health outcomes as well as the trajectory of healthcare spend. Smokers see benefits in improved circulation and lung function within 2 weeks to 3 months of cessation [5]. Also, within 1 year of cessation, smoking-related excess risk of coronary heart disease reduces to half that of a current smoker, and by 5 years, throat, mouth, esophageal, and bladder cancer risks are halved [5]. After 20 years, excess risks for pancreatic cancer, cardiovascular-related mortality, and female mortality are reduced to that of a never smoker [6-8]. The impact of cessation on morbidity and mortality can also have a large effect on healthcare spending. A recent study focusing on smoking and expenditures in the US concluded that a $10 \%$ relative drop in smoking in each state would result in an estimated \$63 billion reduction (in 2012 US dollars) in healthcare costs the following year [9].

Increasing access to smoking cessation tools and resources is integral in promoting smoking cessation, increasing quit rates, and reducing the burden of smoking. An estimated $70 \%$ of smokers want to quit smoking, $42.7 \%$ try to quit each year, and $30.8 \%$ use smoking cessation treatments $[1,10]$. Unaided, the success rate is approximately 5\% [10, 11]. Smoking cessation treatment, including behavioral interventions and US Food and Drug Administration (FDA)-approved pharmacotherapy for cessation, has been rated as one of the most effective preventive health services by the US Preventive Services Task Force [12]. Recognizing the evidence base on the value of pharmacotherapy options, the US Department of Health and Human Services clinical practice guidelines recommend that all smokers trying to quit be given pharmacotherapy for cessation, except 
when medically contraindicated or in special populations with insufficient evidence of effectiveness (i.e., pregnant women, adolescents) [13]. Therefore, it is not unexpected that tobacco cessation services were incorporated as a principle of the Patient Protection and Affordable Care Act (ACA; Pub L No. 111-148) [14].

Under the ACA, tobacco cessation is included as a required preventive service with no patient cost share. Specifically, according to guidance issued in May 2014 by the Departments of Health and Human Services, Labor and Treasury, a health plan will be considered to be in compliance if they cover (1) screening for tobacco use, (2) at least two quit attempts per year that include four sessions of counseling and 90 days of medication per quit attempt, (3) individual or group counseling (at least $10 \mathrm{~min}$ per session), and (4) all FDA-approved tobacco cessation medications (prescription and over the counter) when prescribed by a healthcare provider without prior authorization or patient cost share [15].

Health plans manage health benefits and medication access through their prescription formularies and product coverage and, therefore, play a vital role in supporting smoking cessation. A March 2015 study by the American Lung Association found that less than $20 \%$ of plan insurers were offering sufficient coverage and fewer than 50\% listed the seven approved cessation medications on their formularies [16]. An August 2015 an update to that report found a dramatic increase in the availability of formularies and other documents highlighting coverage for smoking cessation and guidance for subscribers on coverage access for smoking cessation [17].

However, uncertainty remains on the gaps between smoking cessation requirements and what is actually occurring in practice. Further, health plans bear the fiscal burden for operationalizing ACA requirements. The true fiscal impact of adopting ACA requirements is dependent on a multitude of factors, ranging from current patient cost sharing practices to smoking cessation trends to the efficacy of cessation medications. In this study, we first gather data on current cessation patterns as well as real-world drug costs and plan benefit design data to articulate the current cost of providing access to smoking cessation medicines and to highlight the gaps between current coverage and ACA requirements. Next, we estimate the 1to 5-year pharmacy budget impact of providing ACA-required coverage for smoking cessation products to understand the fiscal impact to a US healthcare plan.

\section{METHODS}

\section{Smoking Cessation Budget Impact Model Framework}

A budget impact model was developed in Microsoft Excel $^{\circledR}$ to simulate current and projected costs for health plans covering cessation medicines. The model takes the perspective of a US healthcare payer, using nationally representative default scenarios developed for public (Medicare, Medicaid) and private (commercial) payers. The model leverages a market-based approach to estimate the pharmacy budget impact of providing ACA-required coverage for smoking cessation products. First, the model estimates the current (or baseline) annual budget for a health plan, with assumptions for coverage and smoking cessation product utilization based on current, real-world national and state-level trends. Next, a projected scenario is generated which adjusts the coverage parameters to reflect optimized ACA-required coverage. Finally, the budget 
impact of adopting the ACA-required smoking cessation coverage is the difference between the baseline (current world) and projected (ACA-required) estimates. Model results include the number of smokers attempting to quit with covered products, number of successful quitters, annual costs, and cost per-member per-month (PMPM). Please note that this article does not contain any new studies with human or animal subjects performed by any of the authors but is based on previously published literature.

To simulate patterns for quit attempts, smoking relapse, and cessation success, the model utilizes a Markov methodology with five health states and 6-month cycle lengths (Fig. 1). To estimate the number of successful quitters, the model begins with the entire population of adult smokers. Among the population that attempts to quit, a portion will utilize pharmaceutical smoking cessation medications and the remaining will attempt to quit without aids.

\section{Model Inputs}

Data inputs in the model are populated with information from peer-reviewed literature, publicly available data sources, and the IMS National Prescription Audit ${ }^{\mathrm{TM}}$ (NPA) [18]. The model base-case estimates impact of offering ACA coverage for a hypothetical health plan with 1 million covered lives. A closed cohort model is used, where no smokers enter over time and smokers can only leave as a result of all-cause mortality [19]. This approach helps to isolate the impact of smoking cessation on a given population of smokers over time. Information on the age and gender distribution of the US population from the US census, national estimates for the prevalence of smoking, annual quit attempts, and the utilization of smoking cessation products are leveraged to isolate the population of smokers using smoking cessation products filled by a prescription that would be covered by their health plan $[10,20-22]$. In the base case, the model assumes the same utilization of prescription cessation medications (7.4\%), among the population using prescription and over the counter (OTC) medications, across age groups and payer types [18].

The national commercial and Medicaid population inputs can be found in Table 1. Starting with a hypothetical plan of 1 million

Health State Descriptions:

Eligible Smoker: Adult smokers who are eligible to quit smoking with a smoking cessation aid during the current year. This includes:

(1) Smokers who have never attempted to quit,

(2) Smokers who have previously attempted to quit and failed,

(3) Successful quitters who subsequently relapsed

Ineligible Smoker: This tunnel state is used when modeling one covered quit attempt per year. This state holds smokers who are not eligible to quit smoking because they failed a quit attempt less than 12 months prior to their current quit attempt. When modeling two quit attempts per year, smokers return to 'Eligible Smoker' in the first cycle after their relapse.

Initial Quitter: A tunnel state for smokers who have attempted to quit in the current year, and are currently abstinent from smoking during the current cycle but who have not yet met the criteria for 'Successful Quitter'.

Successful Quitter: Consists of initial quitters who have abstained from smoking for the required length of time to meet the clinical definition of success and who have not relapsed. The model assumes that a person becomes a 'Successful Quitter' after being abstinent from smoking for one full year.

Death: Captures death due to all-cause mortality, based on age- and gender-adjusted rates from US life tables from the Centers for Disease Control and Prevention [19].

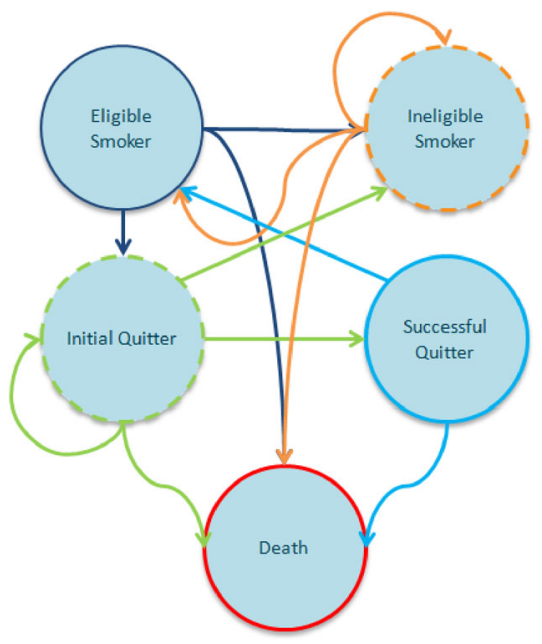

Fig. 1 Markov framework 
covered lives, the model estimates 128,987 adult smokers, 67,004 smokers attempting to quit annually, and 1527 people utilizing smoking cessation medications that were filled via a prescription for commercial and Medicaid plans. The model focuses solely on the use of smoking cessation medications filled via prescription, as these medications would

Table 1 National commercial and Medicaid population inputs

\begin{tabular}{|c|c|c|c|c|c|}
\hline \multicolumn{6}{|c|}{ Inputs to estimate adult smokers (plan of 1 million covered lives) } \\
\hline \multirow[t]{2}{*}{ Population distribution [20] } & \multicolumn{2}{|c|}{ Male population } & \multicolumn{2}{|c|}{ Female population } & \multirow{2}{*}{$\begin{array}{l}\text { Plan population } \\
\text { Males and females }\end{array}$} \\
\hline & $\%$ & No. males & $\%$ & No. females & \\
\hline $0-12$ & 8.33 & 83,339 & 7.98 & 79,762 & 163,101 \\
\hline $13-17$ & 8.29 & 32,892 & 3.15 & 31,487 & 64,379 \\
\hline $18-24$ & 4.90 & 49,028 & 4.65 & 46,491 & 95,519 \\
\hline $25-44$ & 13.28 & 132,753 & 13.10 & 130,960 & 263,713 \\
\hline $45-64$ & 12.73 & 127,289 & 13.35 & 133,465 & 260,754 \\
\hline $65+$ & 6.76 & 67,578 & 8.50 & 84,956 & 152,534 \\
\hline Total adult (18+) & & 376,648 & & 395,872 & 772,520 \\
\hline Prevalence of smoking [21] & $\%$ & $\begin{array}{l}\text { No. male } \\
\text { smokers }\end{array}$ & $\%$ & $\begin{array}{l}\text { No. female } \\
\text { smokers }\end{array}$ & $\begin{array}{l}\text { Male and female } \\
\text { smokers }\end{array}$ \\
\hline $0-12$ & 0.00 & & 0.00 & & 0 \\
\hline $13-17$ & 18.50 & 6085 & 14.80 & 4660 & 10,745 \\
\hline $18-24$ & 18.50 & 9070 & 14.80 & 6881 & 15,951 \\
\hline $25-44$ & 22.90 & 30,400 & 17.20 & 22,525 & 52,926 \\
\hline $45-64$ & 19.40 & 24,694 & 16.80 & 22,422 & 47,116 \\
\hline $65+$ & 9.80 & 6623 & 7.50 & 6372 & 12,994 \\
\hline Total adult $(18+)$ & & 70,787 & & 58,200 & 128,987 \\
\hline
\end{tabular}

Inputs to estimate eligible quitters

\begin{tabular}{|c|c|c|c|c|c|c|}
\hline & \multicolumn{2}{|c|}{$\begin{array}{l}\text { \% attempting } \\
\text { quit annually [22] }\end{array}$} & \multicolumn{2}{|c|}{$\begin{array}{l}\text { \% using smoking } \\
\text { cessation aids }[10]\end{array}$} & \multicolumn{2}{|c|}{$\begin{array}{l}\% \text { using prescription } \\
\text { aids }[18]\end{array}$} \\
\hline & $\%$ & Total quitters & $\%$ & Aids & $\%$ & Quitters \\
\hline $13-24$ & 61.90 & 9874 & 12.70 & 1254 & 7.40 & 93 \\
\hline $25-44$ & 53.30 & 28,209 & 28.30 & 7983 & 7.40 & 591 \\
\hline $45-64$ & 49.00 & 23,037 & 40.40 & 9327 & 7.40 & 690 \\
\hline $65+$ & 44.90 & 5834 & 35.50 & 2071 & 7.40 & 153 \\
\hline Total adult $(13+)$ & & 67,004 & & 20,636 & & 1527 \\
\hline
\end{tabular}

Inputs for estimating eligible quitters represent both male and female populations combined; Information on the number of individuals in the 13-17 age group is collected to allow for patients to age into the model over the 5-year time horizon The model maintains maximum precision in the population calculations. Therefore, numbers may not sum due to rounding 
impact health plan budgets. Any products obtained without a prescription, including some OTC medications, are not considered in the current analysis. Note that although smoking cessation medications are indicated for an adult population (18+), the population ages $13-17$ are estimated to account for individuals who will become 18 years of age and enter the model over the 5-year time horizon. When estimating the eligible population for Medicare plans, we restricted the population to individuals aged 65 , resulting in 85,083 adult smokers, 38,202 total smokers attempting to quit annually, and 1004 individuals utilizing smoking cessation aids filled by a prescription.

The model includes the seven FDA-approved forms of smoking cessation products, including five forms of nicotine replacement therapy (NRT) (patch, gum, lozenge, nasal spray, and inhalers) as well as two non-NRT medications (bupropion SR and varenicline) [13]. Note that OTC NRTs are included to account for NRT therapies being dispensed by prescription and covered under the ACA, as captured in the IMS NPA data [18]. Therefore, while the model only examines smokers utilizing prescription smoking cessation therapies, some OTC medicines are included if they were dispensed with a prescription.

Data on utilization and pricing of smoking cessation medications as well as patient cost share trends are based on IMS NPA data as of January 2016 [18]. Table 2 lists the national commercial inputs for product utilization and cost. Detailed information on market share and drug cost inputs for Medicare and Medicaid scenarios are provided in the Supplementary Appendix. The NPA database contains pharmacy records from over 37,000 retail pharmacies, including independent pharmacies, chain pharmacies, pharmacies in discount outlets, and pharmacies in food stores. Additionally, it includes feeds from mail service houses, pharmacy benefit managers, and long-term care facilities. The national sample includes sources located in all 50 states. It captures approximately $74 \%$ of all prescriptions and projects the remaining $26 \%$. Given that this analysis estimates the cost related to changes in smoking cessation coverage under the ACA, utilization patterns among smoking cessation products (i.e., market shares) are assumed constant over the 5-year model time horizon in the base-case analysis.

Late relapse is used to estimate the number of former smokers who were successful quitters (e.g., have quit for 12 months) but then eventually relapse to account for a return to smoking after a period of initial success. Published data supports the assumption that as the duration of time since quitting increases, relapse decreases. Therefore, an annual relapse rate of $6.3 \%$ based on previously published studies was utilized in the model $[23,24]$.

Smoking cessation intervention efficacy is based on data drawn from a Cochrane systematic review [25]. Systematic reviews were used rather than head-to-head trials to maximize the number of treatments included in the model and to characterize a wide-ranging analysis of available efficacy data. The 12-month quit rate for placebo (9.3\%) was based on a pooled analysis of 52-week continuous abstinence rates from two randomized controlled trials comparing varenicline, bupropion, and placebo [26]. Efficacy information for unaided cessation (5.0\%) was also collected to model cessation patterns for individuals trying to quit smoking without using any cessation medications [11].

All smokers are eligible for quit attempts. The model also includes smokers who attempt to quit without smoking cessation pharmacotherapy to account for smokers who may successfully quit unaided and to accurately 
Table 2 National commercial inputs for product utilization and unit costs [18]

\begin{tabular}{|c|c|c|c|c|c|c|c|}
\hline \multirow[b]{2}{*}{ CESSATION PRODUCT } & \multirow{2}{*}{$\begin{array}{l}\text { Rx per } \\
\text { Therapy }\end{array}$} & \multicolumn{3}{|c|}{ Baseline Scenario } & \multicolumn{3}{|c|}{ Projected Scenario } \\
\hline & & Market Share & $\begin{array}{c}\text { Patient Cost } \\
\text { Share }\end{array}$ & Cost per $\mathrm{Rx}$ & Market Share & $\begin{array}{c}\text { Patient Cost } \\
\text { Share }\end{array}$ & Cost per Rx \\
\hline VARENICLINE & & \multicolumn{2}{|l|}{$68.98 \%$} & & \multicolumn{2}{|l|}{$68.98 \%$} & \\
\hline VARENICLINE TAB FC 1MG & 3 & $36.48 \%$ & $\$ 18.53$ & $\$ 269.62$ & $36.48 \%$ & $\$ 0.00$ & $\$ 288.15$ \\
\hline VARENICLINE DOSEPAK $0.5-1 \mathrm{MG}$ & 3 & $27.75 \%$ & $\$ 19.70$ & $\$ 260.14$ & $27.75 \%$ & $\$ 0.00$ & $\$ 279.84$ \\
\hline VARENICLINE DOSEPAK $1 \mathrm{MG}$ & 3 & $4.75 \%$ & $\$ 15.83$ & $\$ 265.67$ & $4.75 \%$ & $\$ 0.00$ & $\$ 281.50$ \\
\hline BUPROPION & & $4.71 \%$ & & & $4.71 \%$ & $\$ 0.00$ & \\
\hline BUPROBAN TAB SA FC $150 M G$ & 3 & $0.17 \%$ & $\$ 5.32$ & $\$ 25.58$ & $0.17 \%$ & $\$ 0.00$ & $\$ 30.90$ \\
\hline BUPROPION HCL SR Z TAB SA FC $150 M G$ & 3 & $4.51 \%$ & $\$ 4.02$ & $\$ 30.61$ & $4.51 \%$ & $\$ 0.00$ & $\$ 34.63$ \\
\hline ZYBAN TAB SA FC $150 M G$ & 3 & $0.03 \%$ & $\$ 26.43$ & $\$ 176.65$ & $0.03 \%$ & $\$ 0.00$ & $\$ 203.08$ \\
\hline GUM & & $3.13 \%$ & & & $3.13 \%$ & & \\
\hline NICORELIEF GUM 2MG & 3 & $0.10 \%$ & $\$ 0.95$ & $\$ 37.96$ & $0.10 \%$ & $\$ 0.00$ & $\$ 38.91$ \\
\hline NICORELIEF GUM 4MG & 3 & $0.09 \%$ & $\$ 2.17$ & $\$ 39.65$ & $0.09 \%$ & $\$ 0.00$ & $\$ 41.82$ \\
\hline NICORETTE (OTC) GUM 2MG & 3 & $0.17 \%$ & $\$ 2.00$ & $\$ 49.38$ & $0.17 \%$ & $\$ 0.00$ & $\$ 51.38$ \\
\hline NICORETTE (OTC) GUM 4MG & 3 & $0.14 \%$ & $\$ 3.35$ & $\$ 56.81$ & $0.14 \%$ & $\$ 0.00$ & $\$ 60.16$ \\
\hline NICORETTE (OTC) GUM COATED $2 \mathrm{MG}$ & 3 & $0.01 \%$ & $\$ 16.35$ & $\$ 45.32$ & $0.01 \%$ & $\$ 0.00$ & $\$ 61.67$ \\
\hline NICORETTE (OTC) GUM COATED 4MG & 3 & $0.07 \%$ & $\$ 4.16$ & $\$ 62.10$ & $0.07 \%$ & $\$ 0.00$ & $\$ 66.26$ \\
\hline NICOTINE POLAC GUM 2MG & 3 & $1.07 \%$ & $\$ 1.53$ & $\$ 29.74$ & $1.07 \%$ & $\$ 0.00$ & $\$ 31.27$ \\
\hline NICOTINE POLAC GUM 4MG & 3 & $1.15 \%$ & $\$ 1.45$ & $\$ 34.82$ & $1.15 \%$ & $\$ 0.00$ & $\$ 36.27$ \\
\hline NICOTINE POLAC GUM COATED 2MG & 3 & $0.14 \%$ & $\$ 2.09$ & $\$ 32.82$ & $0.14 \%$ & $\$ 0.00$ & $\$ 34.91$ \\
\hline NICOTINE POLAC GUM COATED 4MG & 3 & $0.20 \%$ & $\$ 2.01$ & $\$ 38.91$ & $0.20 \%$ & $\$ 0.00$ & $\$ 40.92$ \\
\hline THRIVE NICOTINE GUM 2MG & 3 & $0.00 \%$ & $\$ 0.00$ & $\$ 35.59$ & $0.00 \%$ & $\$ 0.00$ & $\$ 35.59$ \\
\hline INHALER & & $1.50 \%$ & & & $1.50 \%$ & $\$ 0.00$ & \\
\hline NICOTROL INH 4-WK CART 1OMG & 3 & $1.50 \%$ & $\$ 29.72$ & $\$ 277.38$ & $1.50 \%$ & $\$ 0.00$ & $\$ 307.10$ \\
\hline LOZENGE & & $1.18 \%$ & & & $1.18 \%$ & & \\
\hline NICORETTE (OTC) LOZ MINI $2 \mathrm{MG}$ & 4 & $0.04 \%$ & $\$ 1.38$ & $\$ 50.03$ & $0.04 \%$ & $\$ 0.00$ & $\$ 51.41$ \\
\hline NICORETTE (OTC) LOZ MINI 4MG & 4 & $0.04 \%$ & $\$ 1.18$ & $\$ 50.71$ & $0.04 \%$ & $\$ 0.00$ & $\$ 51.89$ \\
\hline NICORETTE LOZ LOZ 2MG & 4 & $0.01 \%$ & $\$ 4.82$ & $\$ 41.16$ & $0.01 \%$ & $\$ 0.00$ & $\$ 45.98$ \\
\hline NICORETTE LOZ LOZ 4MG & 4 & $0.01 \%$ & $\$ \$ 0.00$ & $\$ 50.76$ & $0.01 \%$ & $\$ 0.00$ & $\$ 50.76$ \\
\hline NICOTINE POLAC LOZ 2MG & 4 & $0.52 \%$ & $\$ 2.32$ & $\$ 37.09$ & $0.52 \%$ & $\$ 0.00$ & $\$ 39.41$ \\
\hline NICOTINE POLAC LOZ 4MG & 4 & $0.54 \%$ & $\$ 1.86$ & $\$ 41.02$ & $0.54 \%$ & $\$ 0.00$ & $\$ 42.88$ \\
\hline NICOTINE POLAC LOZ MINI 2MG & 4 & $0.00 \%$ & $\$ \$ 0.10$ & $\$ 34.84$ & $0.00 \%$ & $\$ 0.00$ & $\$ 34.94$ \\
\hline NICOTINE POLAC LOZ MINI 4MG & 4 & $0.03 \%$ & $\$ 6.18$ & $\$ 27.27$ & $0.03 \%$ & $\$ 0.00$ & $\$ 33.45$ \\
\hline NASAL SPRAY & & $0.48 \%$ & & & $0.48 \%$ & & \\
\hline NICOTROL NS 4-WK MDI NASAL $10 \mathrm{MG} / \mathrm{ML}$ & 3 & $0.48 \%$ & $\$ 52.41$ & $\$ 290.02$ & $0.48 \%$ & $\$ 0.00$ & $\$ 342.43$ \\
\hline
\end{tabular}


Table 2 continued

\begin{tabular}{|c|c|c|c|c|c|c|c|}
\hline \multirow[b]{2}{*}{ CESSATION PRODUCT } & \multirow{2}{*}{$\begin{array}{l}\text { Rx per } \\
\text { Therapy }\end{array}$} & \multicolumn{3}{|c|}{ Baseline Scenario } & \multicolumn{3}{|c|}{ Projected Scenario } \\
\hline & & Market Share & $\begin{array}{c}\text { Patient Cost } \\
\text { Share }\end{array}$ & Cost per $\mathrm{Rx}$ & Market Share & $\begin{array}{c}\text { Patient Cost } \\
\text { Share }\end{array}$ & Cost per $\mathrm{Rx}$ \\
\hline PATCH & & \multicolumn{2}{|l|}{$20.02 \%$} & & \multicolumn{2}{|l|}{$20.02 \%$} & \\
\hline NICODERM CQ CLEAR PATCH $21 \mathrm{MG}$ & 5 & $0.03 \%$ & $\$ 1.86$ & $\$ 61.69$ & $0.03 \%$ & $\$ 0.00$ & $\$ \$ 63.55$ \\
\hline NICODERM CQ PATCH 14MG & 5 & $0.44 \%$ & $\$ 3.02$ & $\$ 56.19$ & $0.44 \%$ & $\$ 0.00$ & $\$ 59.21$ \\
\hline NICODERM CQ PATCH 21MG & 5 & $0.66 \%$ & $\$ 3.38$ & $\$ 62.35$ & $0.66 \%$ & $\$ 0.00$ & $\$ 65.73$ \\
\hline NICODERM CQ PATCH 7MG & 5 & $0.21 \%$ & $\$ 2.05$ & $\$ 50.11$ & $0.21 \%$ & $\$ 0.00$ & $\$ 52.16$ \\
\hline NICODERM PATCH 7MG & 5 & $0.00 \%$ & $\$ 0.00$ & $\$ 84.63$ & $0.00 \%$ & $\$ 0.00$ & $\$ 84.63$ \\
\hline NICOTINE (OTC) PATCH 14MG & 5 & $2.51 \%$ & $\$ 2.45$ & $\$ 36.39$ & $2.51 \%$ & $\$ 0.00$ & $\$ 38.84$ \\
\hline NICOTINE (OTC) PATCH 21MG & 5 & $3.64 \%$ & $\$ 2.86$ & $\$ 38.56$ & $3.64 \%$ & $\$ 0.00$ & $\$ 41.42$ \\
\hline NICOTINE (OTC) PATCH 7MG & 5 & $1.15 \%$ & $\$ 2.31$ & $\$ 32.95$ & $1.15 \%$ & $\$ 0.00$ & $\$ 35.26$ \\
\hline NICOTINE (RX) PATCH 14MG & 5 & $0.00 \%$ & $\$ 0.00$ & $\$ \$ 0.00$ & $0.00 \%$ & $\$ 0.00$ & $\$ 0.00$ \\
\hline NICOTINE (RX) PATCH 21MG & 5 & $0.00 \%$ & $\$ 0.00$ & $\$ 413.28$ & $0.00 \%$ & $\$ 0.00$ & $\$ 413.28$ \\
\hline NICOTINE KIT PATCH UNKNOWN & 5 & $0.01 \%$ & $\$ 15.10$ & $\$ 66.12$ & $0.01 \%$ & $\$ 0.00$ & $\$ 81.22$ \\
\hline NICOTINE PATCH $14 \mathrm{MG}$ & 5 & $2.45 \%$ & $\$ 2.23$ & $\$ 38.13$ & $2.45 \%$ & $\$ 0.00$ & $\$ 40.36$ \\
\hline NICOTINE PATCH $14 \mathrm{MG} / 24 \mathrm{HR}$ & 5 & $0.69 \%$ & $\$ 3.03$ & $\$ 35.61$ & $0.69 \%$ & $\$ 0.00$ & $\$ 38.64$ \\
\hline NICOTINE PATCH 21MG & 5 & $4.54 \%$ & $\$ 4.24$ & $\$ 37.09$ & $4.54 \%$ & $\$ 0.00$ & $\$ 41.33$ \\
\hline NICOTINE PATCH 21MG/24HR & 5 & $1.89 \%$ & $\$ 3.43$ & $\$ 37.63$ & $1.89 \%$ & $\$ 0.00$ & $\$ 41.06$ \\
\hline NICOTINE PATCH 22MG & 5 & $0.12 \%$ & $\$ 0.00$ & $\$ \$ 0.00$ & $0.12 \%$ & $\$ 0.00$ & $\$ 0.00$ \\
\hline NICOTINE PATCH 7MG & 5 & $1.27 \%$ & $\$ 3.70$ & $\$ 30.29$ & $1.27 \%$ & $\$ 0.00$ & $\$ 33.99$ \\
\hline NICOTINE PATCH $7 \mathrm{MG} / 24 \mathrm{HR}$ & 5 & $0.39 \%$ & $\$ 2.87$ & $\$ 31.64$ & $0.39 \%$ & $\$ 0.00$ & $\$ 34.51$ \\
\hline NICOTINE PATCH SEQ, UNKNOWN & 5 & $0.01 \%$ & $\$ 19.03$ & $\$ 43.78$ & $0.01 \%$ & $\$ 0.00$ & $\$ 62.81$ \\
\hline
\end{tabular}

Market shares are assumed constant in the model base case in years 1-5 to isolate the impact of ACA-recommended coverage on plan budgets

Estimates for drug costs per unit, patient cost sharing, and number of units dispensed per prescription are based on national commercial trends in NPA data as of January 2016

Estimates for the number of units per prescription are assumed constant across the baseline and projected scenarios in the base-case analysis

Table 3 Efficacy rates of smoking cessation interventions $[25,26]$

\begin{tabular}{lll}
\hline & Odds ratio & $\begin{array}{l}\text { 12-month quit } \\
\text { rate (\%) }\end{array}$ \\
\hline PLACEBO & N/A & 9.3 \\
VARENICLINE & 2.88 & 22.8 \\
BUPROPION & 1.82 & 15.7 \\
NRT GUM & 1.68 & 14.7 \\
NRT INHALER & 1.84 & 15.9 \\
NRT LOZENGE & 1.84 & 15.9 \\
NRT NASAL SPRAY & 1.84 & 15.9 \\
NRT PATCH & 1.91 & 16.4 \\
\hline
\end{tabular}

model the relapse patterns and additional cessation attempts (with and without smoking cessation medications) for the entire group over the model time horizon. Results from the model represent outcomes only for smokers who attempt to quit using smoking cessation medications filled by prescription to estimate the pharmacy budget impact of smoking cessation coverage to a health plan. Table 3 highlights the efficacy rates of smoking cessation interventions.

\section{Model Base Case}

The inputs and assumptions used in the base-case scenario were chosen to compare the current smoking cessation intervention usage and average patient out of pocket costs and medication unit costs to a projected scenario where health plans follow ACA-required guidance for smoking cessation coverage. The 


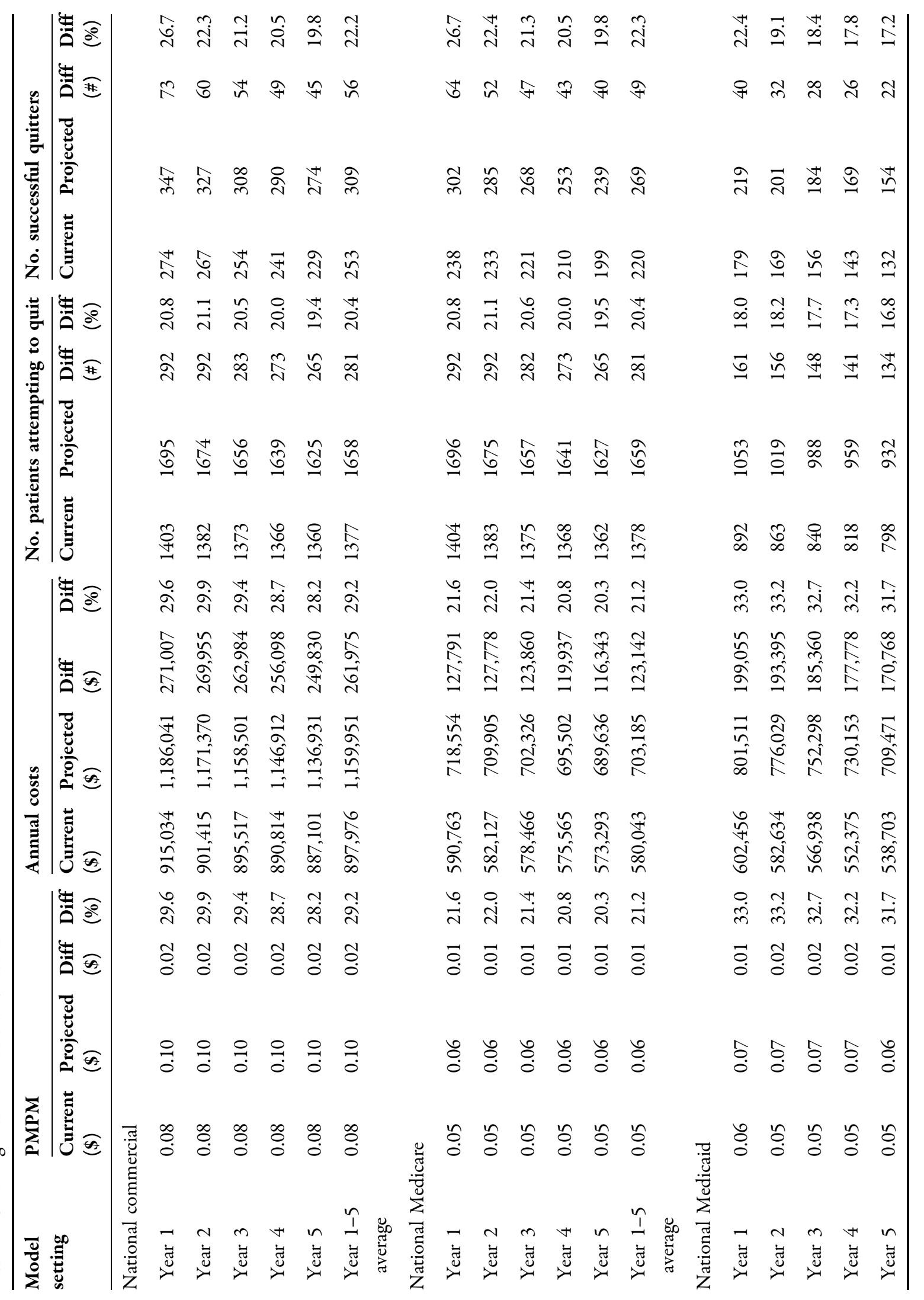




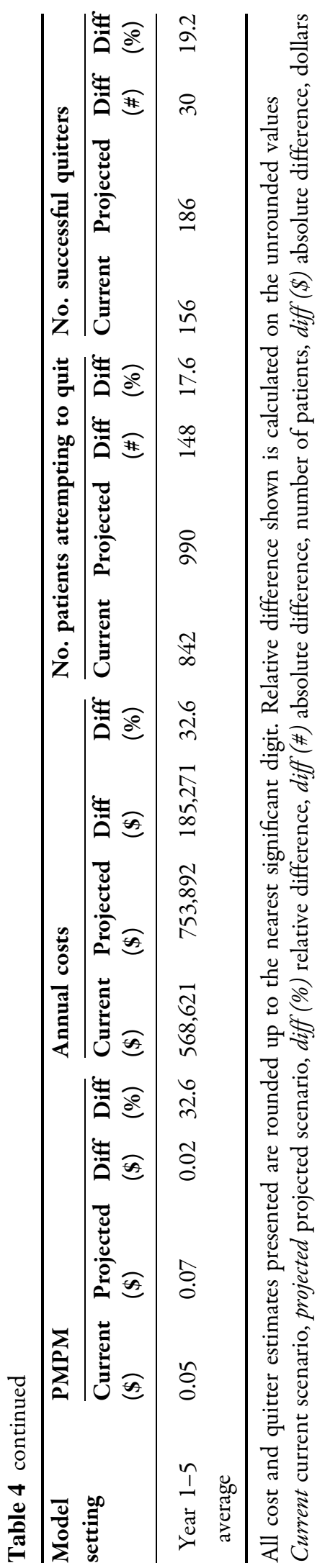

model uses national rates, and by default, the current scenario assumes one quit attempt per year. The projected scenario utilizes inputs and assumptions to reflect optimal ACA coverage, including the removal of all patient cost sharing and ensuring that each quitter is eligible for two covered quit attempts per year.

\section{RESULTS}

For hypothetical nationally representative plans the current total 1- to 5-year average PMPM cost of providing coverage for smoking cessation medications is $\$ 0.08$ for commercial, $\$ 0.05$ for Medicare, and $\$ 0.05$ for Medicaid plans. For the projected scenario based on ACA optimization, the PMPM cost is $\$ 0.10$ for commercial, $\$ 0.06$ for Medicare, and $\$ 0.07$ for Medicaid plans. The resulting incremental PMPM budget impact is low, ranging from $\$ 0.01$ for Medicare to $\$ 0.02$ for commercial and Medicaid payers. The budget impact reflects two covered attempts to quit smoking with no cost share for smoker access to all seven cessation medications. The results reflect a conservative analysis that considers pharmacy costs only, without considering the additional direct medical cost offsets associated with smoking cessation.

Across all 5 years and the scenarios considered, the relative increase in number of successful quitters exceeds the relative increase in the number of smokers attempting to quit. Over 5 years, there is a $20.4 \%$ increase in the number of smokers attempting to quit, and a $22.2 \%$ increase in the number of successful quitters in the commercial plan. Similar trends in smokers attempting to quit and successful quitters are also observed for Medicare $(17.6 \%$ and $19.2 \%$, respectively) and Medicaid (20.4\% and $22.3 \%$, respectively) plans. This reflects smokers' second opportunity to quit smoking with the aid of pharmacotherapy, which 
increases the overall likelihood of quitting. The declining estimates for the total numbers of smokers attempting to quit reflect the closed cohort nature of the model. Within the closed cohort, no new smokers enter but some leave as a result of all-cause mortality. Therefore, the number of smokers, and therefore eligible quitters, is slightly reduced each year. Please see Table 4 for details.

A change in benefit to cover two quit attempts per year increases the number of smokers attempting to quit by approximately $20 \%$ across scenarios and settings. By adopting ACA-required coverage and assuming utilization is held constant, a commercial plan would support a total of 1480 additional quitters over 5 years (an average of 280 per year), while Medicaid and Medicare plans would support 742 (average of 148/year) and 1406 (average of 281/year), respectively.

Primary drivers of differences across scenarios include the eligible population (Medicare is 65 and over), patient cost share, and drug prices and market shares for cessation medications. National commercial plans have a high utilization of varenicline (>68\%), which translates to higher success rates for quitters overall given the higher efficacy rate of varenicline relative to other medications [25]. National Medicare plans also have a high utilization of varenicline ( $>77 \%)$, supporting high quit rates. However, patient cost sharing estimates are notably higher in the Medicare payer population vs. other payers for many products, resulting in a larger relative plan impact PMPM when patient cost sharing is removed. However, the absolute cost for both Medicare and Medicaid coverage is lower compared to commercial plans because the National Medicaid plans use the largest number of patches (over 56\%), which have a lower efficacy rate than varenicline according to
Cochrane meta-analysis, resulting in a lower number of successful quits per eligible quitter [25]. However, patient cost sharing estimates are low for Medicaid plans, mitigating the impact of removing patient co-pays on plan PMPM impact.

\section{DISCUSSION}

Across all three payer scenarios, the PMPM impact is low and the results of our analysis indicate that the economic impact of ACA smoking cessation requirements in health plans is fiscally reasonable. Further, given that the model does not consider the medical cost offsets gained from smoking cessation and evaluates only medication costs, the estimated impact is likely lower than overall gains in cost savings realized by payers when covering smoking cessation treatments. Across all scenarios investigated, increased access to smoking cessation medications and coverage of two quit attempts translated into increases in successful quitters, with relative gains in quitters exceeding relative increases in health plan spend. While information on improvements in outcomes and quality of life resonate with smokers, providers, and healthcare payers alike, healthcare payers must consider the fiscal burden of the initial investment in smoking decisions when operating within limited budgets. Findings of this study reinforce that the impact of adopting the ACA requirements for smoking cessation coverage may have a limited near-term impact on a health plan's budget. Considering the individual and public health benefits of reducing smoking, implementing ACA recommendations seems fiscally reasonable.

To our knowledge, no other studies have examined the impact of adopting the 
ACA-required smoking cessation coverage on healthcare plan budgets. Previously published budget impact models for smoking cessation programs have estimated per member per month impact between $\$ 0.10$ and $\$ 0.40$ on healthcare plans [27]. However, these earlier studies are not directly analogous given differences in the targeted smoking cessation interventions, the cost and utilization patterns for smoking cessation interventions at the time of the study, and the lack of explicit consideration of ACA requirements.

As with any research based on real-world data and economic modeling, this study is subject to several limitations that should be considered when interpreting results. Information on utilization and costs for smoking cessation interventions is based on NPA data. While this data set offers a nationally representative view of real-world trends, it only covers about $74 \%$ of all prescriptions and estimates remaining trends via projections. This analysis does not consider changes in utilization which are likely to occur with the increased benefit under ACA. Direct head-to-head randomized data was not available for all smoking cessation interventions in the model, necessitating the use of information from systematic review and meta-analyses for indirect comparison. The most recent Cochrane review that included all relevant FDA-approved smoking cessation medications was chosen to ensure that a single, robust source leveraged for all comparator efficacy estimates. A series of univariate and multivariate analyses were performed to test the impact of uncertainty on point estimates for smoking cessation medication efficacy on model outcomes. The lower and upper bounds of the $95 \%$ confidence interval for each product were tested in univariate analysis and two multivariate analyses explored the impact of using the lower confidence internal or upper confidence interval for all products simultaneously [25]. While each scenario resulted in slight changes to model results, the net impact on incremental PMPM estimates was \$0.01 PMPM or less across all scenarios. This suggests that the conclusions presented herein remain robust across changes in efficacy point estimates for included products. Further, the model assumes that the impact of non-prescription cessation tools, including counseling, is non-differential across smoking cessation products and does not impact the model estimates. And, finally, the model does not explicitly account for the potential impact of utilization changes, smoker adherence or persistence on the estimated number of successful quitters or the cost of smoking cessation interventions. Utilization changes are likely to occur with the increased benefit under ACA because more patients may utilize smoking cessation therapy when the cost barrier is alleviated.

Even while taking into account these limitations, there are several important implications of this research worth noting. Specific aspects of the ACA requirements are essential to ensuring success with cessation. First, the elimination of cost sharing is foundational to providing access to effective medications and supporting potentially higher quit rates. This was observed in a Cochrane review comparing abstinence rates for individuals with and without full coverage programs. Specifically, the relative risk for abstinence at 6 months or more with full financial coverage compared to no coverage was $2.45 \quad(95 \%$ confidence interval [CI] 1.17-5.12) [28]. There was also a positive effect of full financial interventions on the number of participants making a quit attempt (RR 1.11, 95\% CI 1.04-1.32) and use of smoking cessation 
treatment [28]. Further, access to the full range of pharmacotherapy options can also achieve the goal of long-term abstinence [29]. The US Department of Health and Human Services clinical practice guidelines, as well as recommendations of the ACA, reinforce the importance of providing access to a full range of proven smoking cessation medications $[13,14]$.

From a PMPM perspective, the net impact to a plan increases marginally over all scenarios from $\$ 0.01$ (Medicaid) to $\$ 0.02$ (commercial) when the ACA guidelines are optimized. However, these estimates still fall below the $\$ 0.10$ to $\$ 0.40$ PMPM range seen in previous budget impact models for smoking cessation medications [27]. Given the proven efficacy of pharmacotherapy for smoking cessation, near-term investment in supporting the ACA-required smoking cessation benefits may translate into a long-term return on investment in health and economic outcomes [30]. Changes in healthcare spending are realized quickly after changes in smoking behavior [31-33]. Once patients stop smoking, immediate health benefits are realized and healthcare and societal costs decline [9]. Therefore, health plan policies and benefits that determine and support smoking cessation are essential to help reduce healthcare costs.

\section{CONCLUSION}

This study provides real-world evidence-based information on utilization patterns for prescription smoking cessation products, national average cost, and patient cost sharing. This study also provides direct estimates of the financial impact of adopting ACA-required smoking cessation coverage to a US health plan. This adds a tangible and actionable perspective for plan sponsors and individuals responsible for making budgetary decisions and ultimately supporting efforts to address an ongoing public health dilemma.

\section{ACKNOWLEDGEMENTS}

Sponsorship, article processing charges, and the open access charge for this study were funded by Pfizer Inc. All named authors meet the International Committee of Medical Journal Editors (ICMJE) criteria for authorship for this manuscript, take responsibility for the integrity of the work as a whole, and have given final approval to the version to be published.

Disclosures. C.L. Baker and M. Bruno are employees and stockholders of Pfizer Inc. C.P. Ferrufino and S. Kowal are employees of IMS Health, which received funding from Pfizer for conducting this study and for the development of this manuscript.

Compliance with Ethics Guidelines. This article does not contain any new studies with human or animal subjects performed by any of the authors.

Data Availability. Unpublished data from this study, specifically market share and daily average consumption data for prescription smoking cessation products, can be made available to editors and reviewers upon request to the corresponding author.

Open Access. This article is distributed under the terms of the Creative Commons Attribution-NonCommercial 4.0 International License (http://creativecommons.org/licenses/ by-nc/4.0/), which permits any noncommercial use, distribution, and reproduction in any medium, provided you give appropriate credit 
to the original author(s) and the source, provide a link to the Creative Commons license, and indicate if changes were made.

\section{REFERENCES}

1. US Department of Health and Human Services. The health consequences of smoking-50 years of progress: a report of the Surgeon General. Atlanta, GA: US Department of Health and Human Services, Centers for Disease Control and Prevention, National Center for Chronic Disease Prevention and Health Promotion, Office on Smoking and Health. 2014;17.

2. Kochanek KD, Xu J, Murphy SL, Miniño AM, Kung HC. Deaths: final data for 2009. Natl Vital Stat Rep. 2011;60(3):1-16.

3. Carter BD, Abnet CC, Feskanich D, et al. Smoking and mortality-beyond established causes. N Engl J Med. 2015;372(7):631-40.

4. Centers for Disease Control and Prevention, US Department of Health and Human Services [Internet]. Early release of selected estimates based on data from the 2015 National Health Interview Survey. http://www.cdc.gov/. Published 24 May 2016; Accessed 23 June 2016.

5. American Cancer Society [Internet]. Guide to Quitting Smoking. http://www.cancer.org/. Publication date unknown; Accessed 23 June 2016.

6. Kenfield SA, Stampfer MJ, Rosner BA, Colditz GA. Smoking and smoking cessation in relation to mortality in women. JAMA. 2008;299(17):2037-47.

7. Bosetti C, Lucenteforte E, Silverman DT, et al. Cigarette smoking and pancreatic cancer: an analysis from the International Pancreatic Cancer Case-Control Consortium (Panc4). Ann Oncol. 2012;23(7):1880-8.

8. Mons U, Müezzinler A, Gellert C, et al. Impact of smoking and smoking cessation on cardiovascular events and mortality among older adults: meta-analysis of individual participant data from prospective cohort studies of the CHANCES consortium. BMJ. 2015;350:h1551.

9. Lightwood J, Glantz SA. Smoking behavior and healthcare expenditure in the United States, 1992-2009: Panel data estimates. PLoS Med. 2016;13(5):e1002020.

10. Centers for Disease Control and Prevention (CDC). Quitting smoking among adults-United States,
2001-2010. MMWR Morb Mortal Wkly Rep. 2011;60(44):1513.

11. Foulds J, Burke M, Steinberg M, Williams JM, Ziedonis DM. Advances in pharmacotherapy for tobacco dependence. Expert Opin Emerg Drugs. 2004;9(1):39-53.

12. US Preventive Services Task Force [Internet]. Final recommendation statement: tobacco smoking in adults and pregnant women: behavioral and pharmacotherapy interventions. http://www. uspreventiveservicestaskforce.org/. Published 30 Dec 2013; Accessed 22 June 2016.

13. Agency for Healthcare Research and Quality [Internet]. Treating tobacco use and dependence: 2008 update. http://www.ahrq.gov/. Publication date unknown; Accessed 22 June 2016.

14. Lemaire RH, Bailey L, Leischow SJ. Meeting the tobacco cessation coverage requirement of the Patient Protection and Affordable Care Act: state smoking cessation quitlines and cost sharing. Am J Public Health. 2015;105(S5):S699-705.

15. United States Department of Labor [Internet]. FAQs about Affordable Care Act implementation (Part XIX). http://www.dol.gov/. Published 2 May 2014; Accessed 22 June 2016.

16. American Lung Association [Internet]. Report: state health insurance marketplace plans could help more smokers quit. http://www.lung.org/. Published 31 March 2015; Accessed 22 June 2016.

17. American Lung Association [Internet]. Report: state health insurance marketplace plans: new opportunities to help smokers quit. http://www. lung.org/. Published August 2015; Accessed 22 June 2016.

18. IMS Health. National Prescription Audit (All Channels). 2015 (unpublished).

19. Arias E. United States life tables, 2010. Natl Vital Stat Rep. 2014;63(7):1-63.

20. U.S. Census Bureau [Internet] . 2014 national population projections: projected population by single year of age, sex, race, and Hispanic origin for the United States: 2014 to 2060. http://www. census.gov/. Published December 2014; Accessed 2 March 2016.

21. Jamal A, Homa DM, O'Connor E, et al. Current cigarette smoking among adults-United States, 2005-2014. MMWR Morb Mortal Wkly Rep. 2015;64(44):1233-40.

22. Healthy People 2020 [Internet]. Washington, DC: US Department of Health and Human Services, 
Office of Disease Prevention and Health Promotion. www.healthypeople.gov/. Accessed 2 March 2016.

23. Wetter DW, Cofta-Gunn L, Fouladi RT, Cinciripini PM, Sui D, Gritz ER. Late relapse/sustained abstinence among former smokers: a longitudinal study. Prev Med. 2004;39(6):1156-63.

24. Howard MP, Knight C, Boler A, Baker C. Cost-utility analysis of varenicline versus existing smoking cessation strategies using the BENESCO simulation model. Pharmacoeconomics. 2008;26(6):497-511.

25. Cahill K, Stevens S, Perera R, Lancaster $T$. Pharmacological interventions for smoking cessation: an overview and network meta-analysis. Cochrane Database Syst Rev. 2013;CD009329.

26. Nides M, Glover ED, Reus VI, et al. Varenicline versus bupropion SR or placebo for smoking cessation: a pooled analysis. Am J Health Behav. 2008;32(6):664-75.

27. Centers for Disease Control and Prevention [Internet]. What is the role of health insurance coverage in tobacco use cessation? http://www.cdc. gov/tobacco/quit_smoking/cessation/coverage/ page2. Published 29 May 2009; Accessed 18 May 2016.
28. Reda AA, Kaper J, Fikretler H, Severens JL, van Schayck CP. Healthcare financing systems for increasing the use of tobacco dependence treatment. Cochrane Database Syst Rev. 2009;CD004305.

29. Fiore MC, Jaén CR. A clinical blueprint to accelerate the elimination of tobacco use. JAMA. 2008;299(17):2083-5.

30. Aubin HJ, Luquiens A, Berlin I. Pharmacotherapy for smoking cessation: pharmacological principles and clinical practice. Br J Clin Pharmacol. 2014;77(2):324-36.

31. Lightwood JM, Dinno A, Glantz SA. Effect of the California tobacco control program on personal health care expenditures. PLoS Med. 2008;5(8):e178.

32. Lightwood J, Glantz SA. The effect of the California tobacco control program on smoking prevalence, cigarette consumption, and healthcare costs: 1989-2008. PLoS One. 2013;8(2):e47145.

33. Lightwood J, Glantz S. Effect of the Arizona tobacco control program on cigarette consumption and healthcare expenditures. Soc Sci Med. 2011;72(2):166-72. 